\title{
Survival analysis of disease modifying antirheumatic drugs in Spanish rheumatoid arthritis patients
}

\author{
José De La Mata, Francisco J Blanco, Juan J Gómez-Reino
}

\begin{abstract}
Objectives-To evaluate the duration of treatment and the reasons for discontinuing therapy with disease modifying antirheumatic drugs in Spanish rheumatoid arthritis patients.

Methods-An observational study was made of 629 patients with rheumatoid arthritis treated with disease modifying antirheumatic drugs between 1979 and 1991. The outcomes (treatment termination because of toxicity and lack of response) of 991 treatment starts with intramuscular gold salts, D-penicillamine, azathioprine, and methotrexate were subjected to survival analysis. Cumulative probability of continuation of each drug (drug survival) was calculated by the Kaplan-Meier method and comparison between the survival curve of each was made by log rank testing.
\end{abstract}

Results-Median drug survival (95\% confidence interval) was 51 (25-76.9) months for methotrexate, $39.9(19.9-48 \cdot 2)$ months for azathioprine, $34.9(29.4-41.4)$ months for gold salts, and 16.4 (13.9-21) months for D-penicillamine. The highest cumulative probability of drug survival at five years was for methotrexate $(45 \%)$; that at 10 years was for gold salts (15\%). Up to $60 \%$ of the patients discontinued D-penicillamine in the first two years. Lack of response was the major limiting factor for all drugs except D-penicillamine, for which it was toxicity. D-Penicillamine was associated with a greater rate of discontinuations because of toxicity in women and patients older than 65. Previous disease modifying antirheumatic drug administration did not influence current drug survival.

Conclusion-Overall, gold salts remain useful for the treatment of rheumatoid arthritis over long periods of time in the population studied. Because of the high rate of continuation of treatment (survival) and the optimal efficacy and toxicity profiles observed with methotrexate after five years of treatment, it should be the drug of first choice for second line treatment of these RA patients.

(Ann Rheum Dis 1995; 54: 881-885)

Rheumatoid arthritis (RA) is a chronic progressive disease that requires long term treatment. The major concern in management is to control disease activity. ${ }^{1-4}$ Current available data show that disease modifying antirheumatic drugs (DMARDs) are useful in short term studies, ${ }^{5-11}$ but they are seldom continued for long periods, as a result of lack of efficacy, or toxicity. Clinical trials have been unable to show notable advantages of one DMARD over another, ${ }^{12}$ therefore choice of a DMARD should be based on maximal efficacy with minimum toxicity. In this regard, most authors have stressed the need for long term comparative studies; ${ }^{13-15}$ however, such studies under 'controlled' conditions are impractical because of high costs and logistic complexity. As an alternative, community based studies that analyse continuation on treatment with different DMARDs and use long follow ups and large numbers of patients are a common and useful approach to monitoring long term treatment of RA. ${ }^{16-19}$

To assess the long term effectiveness of DMARDs in our population, we conducted an observational study of a large sample of Spanish RA patients followed for 12 years in a single rheumatology unit. We compared the survival (that is, continuation as treatment) of most DMARDs currently used in our community, and analysed the reasons for their discontinuation. To simplify terminology in this text, phrases such as 'drug survival' are used to imply 'cumulative probability of the patient continuing to take the drug'.

\section{Patients and methods}

PATIENTS AND DOSING SCHEDULES

In this open observational study, we reviewed the records of all RA patients treated consecutively in our institution with gold salts, D-penicillamine, azathioprine, and methotrexate from 1979 to 1991 (treatments with methotrexate started in 1986). By December 1991, 629 patients with definite or classical RA according to 1958 American Rheumatism Association criteria received 991 treatment starts as follows: 535 treatments with gold salts, 178 with D-penicillamine, 126 with azathioprine, and 152 with methotrexate. Short breaks in a course of DMARD treatment (usually four weeks or less) were counted as time taking the drug; only 'new starts', not those restarts, were included in the study analysis. The DMARD used was chosen according to the physician's preference. When treatment was not effective or could not be continued because of toxicity, another 
Table 1 Patient characteristics at the start of treatment with disease modifying antirheumatic drugs

\begin{tabular}{lcccc}
\hline & $G S$ & $D-P N$ & $A Z A$ & MTXS \\
\hline Number of starts & 535 & 178 & 126 & 152 \\
Observation period (patient years) & 1405 & 360 & 282 & 272 \\
Sex ratio (F:M) & $3: 1$ & $4: 1$ & $4: 1$ & $5 \cdot 6: 1^{\star}$ \\
<65 years (\%) & 65 & 63 & 60 & $77^{\star}$ \\
\hline
\end{tabular}

GS = Gold salts D-PN = D-penicillamine; $A Z A=$ azathioprine; $M T X=$ methotrexate SMTX was started in 1986. ${ }^{\star} \mathrm{p}<0.05$ compared with GS, D-PN, or AZA $\left(\chi^{2}\right)$.

DMARD was substituted, with one month free from second line medication.

Gold salts were started at a dose of $50 \mathrm{mg} /$ week, decreasing to a minimum of $25 \mathrm{mg}$ monthly if the disease was controlled clinically; D-penicillamine was started at $250 \mathrm{mg}$ daily, with three monthly increments of $125 \mathrm{mg}$, to a maximum of $750 \mathrm{mg}$ daily; azathioprine was prescribed at $75 \mathrm{mg}$ daily, with monthly increments of $25 \mathrm{mg}$ to a maximum of $150 \mathrm{mg}$ daily; and methotrexate was administered at $7.5 \mathrm{mg}$ weekly, with increments of $2.5 \mathrm{mg}$ to a maximum of $15 \mathrm{mg}$ weekly.

Clinical data for the study were obtained every three to four months during clinic visits. The use of DMARDs was recorded using specific data collection forms, each of which noted date of start, maximal dose administered, date and reason for discontinuation, and side effects. The latter were monitored periodically for each drug. Complete blood cell counts and urine analysis were performed at six week intervals in patients receiving gold salts or D-penicillamine. Blood counts were obtained monthly in patients receiving azathioprine. Complete blood cell counts and serum levels of transaminases, alkaline phosphatase, bilirubin, albumin, and creatinine were performed every month in patients taking methotrexate.

CRITERIA FOR DISCONTINUATION OF

TREATMENT

Reasons for termination of treatment were classified as associated toxicity, lack of response, or miscellaneous.

Associated toxicity comprised any adverse effect that required discontinuation of treatment. Results were expressed as number of events per 1000 patient years of observation.

Lack of response was defined as the absence of clinical benefit at any time of follow up after a minimum of six months receiving treatment, or disease relapses not effectively controlled by adjustment of the dose of DMARD.

Miscellaneous causes included loss to follow up, lack of compliance, or death for unrelated reasons while the patients was receiving DMARD treatment.

\section{STATISTICAL ANALYSES}

Survival analysis for the four DMARDs was calculated by the Kaplan-Meier method and expressed as cumulative probability of drug survival. Patients still taking the drug at the end of the study period were excluded from the analyses. An initial analysis took drug discontinuation as the end point. In subsequent analyses, we used termination of treatment because of toxicity or lack of response as outcomes. Differences between drug survival curves were analysed by log rank method, and median survival time was determined by Kaplan-Meier analysis. Comparisons among groups for continuous variables were made by $t$ test. Categorical variables were analysed by the $\chi^{2}$ test. Statistical significance was assumed for values of $p<0.05$.

\section{Results}

PATIENTS

During the study period, DMARDs were started 991 times in 629 RA patients (table 1). No differences in demographic characteristics of the patients or pattern of drug use were observed. More than $75 \%$ of the patients were treated concomitantly with non-steroidal antiinflammatory drugs (NSAIDs); prednisone was prescribed in fewer than $15 \%$ of these, at doses generally less than $10 \mathrm{mg} /$ day. No statistical differences related to gender or age were found in the use of gold salts, D-penicillamine and azathioprine, but methotrexate was prescribed more frequently for women and for patients younger than 65 years $\left(\chi^{2}, \mathrm{p}<0.05\right)$ (table 1$)$.

SURVIVAL ANALYSIS

Figure 1A represents the cumulative probability of survival for the four drugs, taking drug discontinuation as the end point. Drug survival for D-pencillamine was significantly lower than that of the other DMARDs when survival curves were compared by log rank test $(p<0.01)$. Median survivals indicated that more than $50 \%$ of the patients stopped taking D-penicillamine after only 18 months of treatment (table 2). In contrast, $50 \%$ of patients taking methotrexate remained on the treatment after more than 50 months (table 2). After 34 months of treatment, $50 \%$ of patients receiving gold salts or azathioprine were still taking the drug (fig $1 \mathrm{~A}$ ).

REASON FOR DMARD DISCONTINUATION

We recorded 573 discontinuations after a total of 991 starts of DMARD treatment. In most cases, gold salts, azathioprine and methotrexate were discontinued because of lack of response. Among patients receiving D-penicillamine, there were as many discontinuations because of toxicity as there were discontinuations because of lack of response ( $46 \%$ each) (table 3 ). No differences between the four drugs were found when survival curves were compared taking lack of response as the

Table 2 Median survival of treatment with disease modifying antirheumatic drugs (DMARD)

\begin{tabular}{lll}
\hline DMARD & $\begin{array}{l}\text { Median } \\
\text { (months) }\end{array}$ & $95 \%$ Confidence interval \\
\hline Gold salts & 34.9 & 29.4 to 41.4 \\
D-Pencillamine & 16.4 & 13.9 to 21.1 \\
Azathioprine & 39.9 & 19.9 to $48 \cdot 2$ \\
Methotrexate & 51.1 & 25.1 to 76.9 \\
\hline
\end{tabular}



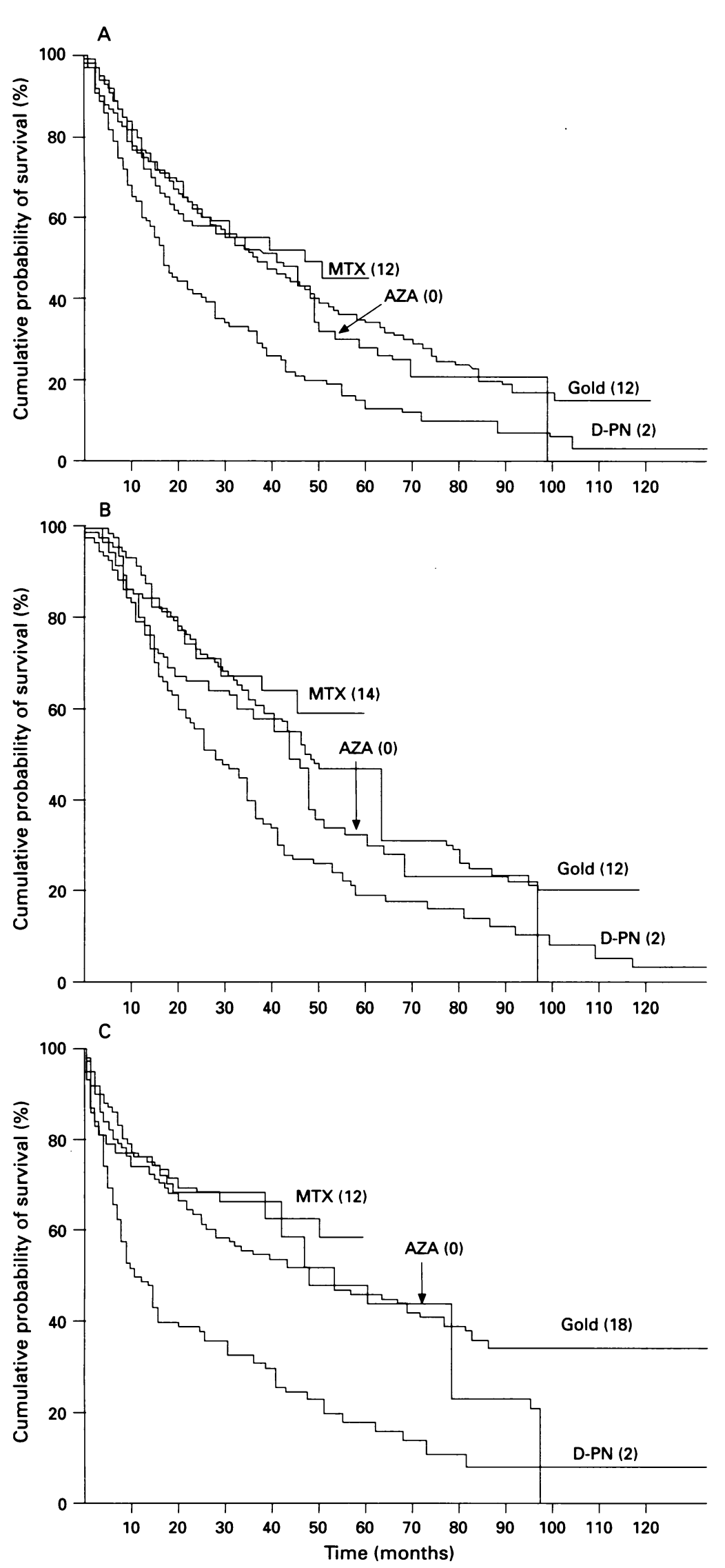

Cumulative probability of patient continuing to take disease modifying antirheumatic drugs (DMARDs). Number of starts $=991$, each panel. Numbers in parentheses represent number of patients still taking the drug from the beginning of the follow up. $M T X=$ Methotrexate; $A Z A=$ azathioprine; $D-P N=D$-penicillamine. A: Drug discontinuation as end point. Number of discontinuations $=573 . D-P N$ significantly different from other drugs (log rank, $p<0 \cdot 01$ ). B: Lack of response as end point. Number of discontinuations $=285$. No difference between drugs. C: Toxicity as end point. Number of discontinuations $=220 . D-P N$ significantly different from other drugs (log rank, $p<0 \cdot 01$ ). end point, (fig 1B), but when toxicity was the end point, drug survival of D-penicillamine was statistically lower than that of the other DMARDs ( $\log$ rank, $\mathrm{p}<0.01$ ) (fig $1 \mathrm{C}$ ). During the first 12 months of treatment with D-penicillamine, up to $50 \%$ of discontinuations were due to associated toxicity, while only about $25 \%$ of patients had discontinued taking other DMARD treatments in the same period. Thereafter, D-penicillamine was associated with a rate of discontinuations similar to that of the other drugs, represented by the progressive flattening of the survival curve beyond the first year of treatment (fig 1C). Table 4 shows the toxicity profiles of the four DMARDs. Mucocutaneous abnormalities were the main reason for discontinuation of gold salts and D-penicillamine. The incidence of gastrointestinal side effects was significantly greater with azathioprine $\left(x^{2}\right.$ test, $\left.\mathrm{p}<0.05\right)$, though gastrointestinal intolerance was also the major limiting factor for patients treated with methotrexate. Proteinuria was more frequent with D-penicillamine than with gold salts $\left(\chi^{2}\right.$ test, $p<0.05)$. Bone marrow aplasia occurred during azathioprine treatment in two patients simultaneously treated with allopurinol. Four patients taking gold salts and two taking D-penicillamine developed pancytopenia. No deaths could be attributed to DMARD treatment. Miscellaneous reasons for discontinuing a drug included loss to follow up, lack of compliance, and death for unrelated reasons while receiving treatment. The percentage of discontinuations for miscellaneous reasons appeared to be greater for azathioprine than for the other treatments (table 3); however, analysis of the reasons revealed proportions of loss to follow up, lack of compliance, or deaths that were similar for azathioprine and the other DMARDs. The low percentage of discontinuations because of toxicity associated with this treatment may have distorted this finding with azathioprine.

INFLUENCE OF GENDER, AGE OR RANK ORDER OF PRESCRIPTION ON SURVIVAL

Women, and patients older than 65 years, had a significantly greater probability of discontinuing D-penicillamine than did men or patients younger than 65 years $\left(\chi^{2}\right.$ test, $\mathrm{p}<0.01$ ) (table 5). Influence of gender or age on survival did not occur with methotrexate, though it was administered significantly more often to women younger than 65 years. Rank order of prescription did not significantly affect any drug survival. Patients who received gold salts or D-penicillamine as a third treatment, and those in whom azathioprine or methotrexate were used as a fourth treatment could not be included for analysis because of the small size of the samples.

\section{Discussion}

The present study has summarised the experience of a single rheumatology unit in the long term management of treatment with 
Table 3 Reasons for discontinuation of disease modifying antirheumatic drug (DMARD) treatment during follow up

\begin{tabular}{lrrrl}
\hline DMARD & Number & $\begin{array}{l}\text { Lack of } \\
\text { response }\end{array}$ & Toxicity & Miscellaneous \\
\hline Gold salts & 313 & $159(51 \%)$ & $121(39 \%)$ & $33(11 \%)$ \\
D-Penicillamine & 142 & $65(46 \%)$ & $66(46 \%)$ & $11(7 \%)$ \\
Azathioprine & 67 & $39(58 \%)$ & $14(21 \%)$ & $14(21 \%)$ \\
Methotrexate & 51 & $22(43 \%)$ & $19(37 \%)$ & $10(20 \%)$ \\
Total & 573 & 285 & 220 & 68 \\
\hline
\end{tabular}

Table 4 Disease modifying antirheumatic drug discontinuations by toxic effects per 1000 patient years $(p \cdot y r)$ of observation

\begin{tabular}{lllll}
\hline & $\begin{array}{l}G S \\
(p \cdot y r=1405) \\
(n=535)\end{array}$ & $\begin{array}{l}D-P N \\
(p \cdot y r=360) \\
(n=178)\end{array}$ & $\begin{array}{l}A Z A \\
(p \cdot y r=282) \\
(n=126)\end{array}$ & $\begin{array}{l}M T X \\
(p \cdot y r=272) \\
(n=152)\end{array}$ \\
\hline Cutaneous & 125 & 140 & - & 26 \\
Oral ulcers & 24 & 61 & - & 32 \\
Proteinuria & 24 & $66^{\star}$ & - & - \\
Gastrointestinal & - & 38 & $78 \dagger$ & 39 \\
Haematological & 18 & - & - & 26 \\
Pulmonary & 2 & - & - & 26 \\
Abnormal liver function tests & - & - & -
\end{tabular}

GS = Gold salts; D-PN = D-penicillamine; $\mathrm{AZA}=$ azathioprine; $\mathrm{MTX}=$ methotrexate. $\mathrm{n}:$ Number of starts.

$\mathrm{p}<0.05$ compared with: ${ }^{\star} \mathrm{GS}$; †D-PN or MTX $\left(\chi^{2}\right)$.

DMARDs in a large sample of Spanish RA patients. Conclusions regarding toxicity and efficacy should be drawn with caution because of various aspects of the study design. The decision to start or to stop treatment was guided by objective factors, but was based finally on the physician's clinical opinion, and thus a possible influence of the physician on the results cannot be excluded; other variables characteristic of retrospective study designs, may also have limited the ability of the study to assess the efficacy of drugs. Nevertheless, our findings may provide useful information on long term RA treatment because of the long term follow up, the large number of patients involved, and the clinical practice setting.

Criteria for the assignment of cause for drug discontinuation have varied from report to report $^{12}$ and this should be borne in mind when the results of our survival analysis are compared with those of previous reports. Overall, our findings on drug survival, taking termination of treatment as the end point, presented no major differences compared with previous reports. Of interest, however, was the high median survivals of gold salts and azathioprine in our analysis. Depending on whether a study is based in a referral centre or in private practice, median survival for gold salts may vary from less than 14 months ${ }^{16} 20-24$ to 24 months. ${ }^{18}{ }^{19}$ In our study, within a public health care system, $50 \%$ of patients continued to take gold salts after 35 months and $38 \%$ after 60 months. Azathioprine survival was also

Table 5 Discontinuations of disease modifying antirheumatic drugs (DMARD) by gender and age

\begin{tabular}{|c|c|c|c|c|c|c|c|c|}
\hline \multirow[t]{3}{*}{$D M A R D$} & \multicolumn{4}{|c|}{ Gender } & \multicolumn{4}{|c|}{ Age (yr) } \\
\hline & \multicolumn{2}{|c|}{ Male } & \multicolumn{2}{|c|}{ Female } & \multicolumn{2}{|l|}{$<65$} & \multicolumn{2}{|l|}{$>65$} \\
\hline & $n$ & $\%$ & $n$ & $\%$ & $n$ & $\%$ & $n$ & $\%$ \\
\hline $\begin{array}{l}\text { Gold salts } \\
\text { D-Penicillamine } \\
\text { Methotrexate } \\
\text { Azathioprine }\end{array}$ & $\begin{array}{r}133 \\
35 \\
24 \\
26\end{array}$ & $\begin{array}{l}51 \\
69 \\
42 \\
39\end{array}$ & $\begin{array}{l}402 \\
143 \\
128 \\
100\end{array}$ & $\begin{array}{l}61 \\
83^{\star \star} \\
57 \\
33\end{array}$ & $\begin{array}{r}187 \\
112 \\
117 \\
76\end{array}$ & $\begin{array}{l}61 \\
78 \\
50 \\
34\end{array}$ & $\begin{array}{r}348 \\
66 \\
35 \\
50\end{array}$ & $\begin{array}{l}58 \\
84^{\star \star} \\
63 \\
35\end{array}$ \\
\hline
\end{tabular}

Values are number of patients analysed, and percentage of patients who discontinued DMARDs. ${ }_{\star \star} \mathrm{p}<0.01$, D-penicillamine compared with the other DMARD $\left(\chi^{2}\right)$. unusual, with a median survival of 39.9 months compared with the eight to 24 months reported previously. ${ }^{11} 192025$ However, our findings for D-penicillamine and methotrexate were in keeping with those of others. ${ }^{78} 141618202123$

A variety of factors may explain these differences. Environmental factors and genetic characteristics of the patients may be relevant: obesity, alcohol intake, or intercurrent diseases may have acted as modifiers of DMARD survival in our population to explain these variations, while genetic factors such as HLA antigens may underlie certain patterns of toxicity. ${ }^{26}$ In RA, South European populations differ from North European white populations in the distribution of HLA DR antigens. ${ }^{27} 28$ Our population was drawn from a South European ethnic group; whether this is associated with differences in drug survival remains to be proved. The study design and the nature of the system of health care provision may also account for variations in drug survival. Our data on gold salts survival suggest that the system of health care provision may influence drug survival. We did not analyse this particular issue, but it merits further evaluation in prospective studies.

Survival analysis using associated toxicity as the end point revealed D-penicillamine to have the poorest survival of all the DMARDs studied. The fact that most discontinuations occurred within the first two years of treatment, and $50 \%$ of them in the first 12 months, suggests that probability of discontinuation because of toxicity in patients receiving D-penicillamine should be expected within the first 18 to 24 months of treatment. This finding is in contrast with those for the other DMARDs studied, with which discontinuations because of side effects occurred gradually over their period of use. Age and gender may predispose to a greater incidence of adverse reactions to drugs, ${ }^{29}$ but we observed a consistent effect only in patients receiving D-penicillamine, among whom women, and patients older than 65 , had a higher rate of drug discontinuation because of associated toxicity. Overall, we found a profile of associated toxicity leading to discontinuation that was in agreement with other reports. ${ }^{18} 193031$

Survival analysis with lack of response as an end point showed a similar survival on treatment for all the DMARDs studied, during the first four years of follow up; at five years, the worst survival was of D-penicillamine and the best, methotrexate. These findings should be interpreted with caution, as the assignment criteria may have constituted a source of bias. Drug discontinuations attributed to lack of response were in patients in whom there was absence of initial response, or loss of efficacy with time over the same period, but it is conceivable that on some occasions the drug was stopped in patients who presented both mild associated toxicity and a lesser measurable therapeutic effect. In those cases, designation of the reason for drug discontinuation may have been arbitrary. Nevertheless, our findings confirm previous reports 
indicating that discontinuations due to lack of response were fewer in patients treated with methotrexate after five years of treatment. ${ }^{9} 1118 \quad 1932-35$ They also indicate that gold salts and azathioprine remain effective in long term use.

In summary, our long term follow up of DMARD treatment in Spanish RA patients showed that median survival on treatment exceeded 34 months for gold salts and azathioprine, and 50 months for methotrexate; that up to $60 \%$ of the patients discontinued D-penicillamine in the first two years of treatment, mainly because of toxicity; and that gender and age influenced drug survival only in patients treated with D-penicillamine, among whom women, and patients older than 65 years, presented a greater rate of discontinuations.

Because this was an open prospective observational study, conclusions regarding toxicity or efficacy of DMARDs should be interpreted with caution. Nevertheless, such studies represent one approach to the assessment of long term likelihood of drug continuation in clinical practice. In view of the differences we detected, the effects of factors such as genetic background, environment, or system of provision of medical care should be evaluated further.

This work was supported in part by an FIS grant (92/0004/04) from the Ministerio de Sanidad y Consumo (Spain).

1 Paulus $\mathrm{H}$. An overview of benefit/risk of disease modifying treatment of rheumatoid arthritis as of today. Ann Rheum treatment of rheumatoid arthris

2 Scott D L, Coulton B L, Symmons D P M, Popert A J. Long-term outcome of treating rheumatoid arthritis: results after 20 years. Lancet 1987 ; 1: 1108-11.

3 Wilske K R, Healey L A. The need for aggressive therapy of rheumatoid arthritis. Rheum Dis Clin North Am 1993; 19: 153-61.

4 Kushner I K, Dawson N V. Aggressive therapy does not substantially alter the long-term course of rheumatoid arthritis. So what else is new? Rheum Dis Clin North Am 1993; 19: 163-71.

5 The Cooperating Clinics Committee of the American Rheumatism Association. A controlled trial of gold salt therapy in rheumatoid arthritis. Arthritis Rheum 1973; 16: therapy in

6 Williams H J, Ward J R. Comparison of oral and parenteral gold therapy and placebo in the treatment of rheumatoid arthritis. Scand F Rheumatol 1983; (suppl) 51: 92-9.

7 Dixon A S J, Davies J, Dormandy T L, et al. Synthetic $\mathrm{D}(-)$ penicillamine in rheumatoid arthritis: double-blind controlled study of high and low dosage regimen. $A n n$ Rheum Dis 1975; 34: 416-21.

8 Shiokowa Y, Horiuchi Y, Honma M, Kageyama T, Okada T, Azuma T. Clinical evaluation of D-penicillamine by multicentric double blind comparative study in chronic rheumatoid arthritis. Arthritis Rheum 1977; 20: 1464-72.

9 Weinblatt M E, Coblyn J S, Fox D A, et al. Efficacy of lowdose methotrexate in rheumatoid arthritis. $N$ Engl 7 Med 1985; 312: 818-22.

10 Plaulus H E, Williams H J, Ward J R, et al. Azathioprine versus D-penicillamine in rheumatoid arthritis patients who have been treated unsuccessfully with gold. Arthritis Rheum 1984; 27: 721-7.

11 Hamdy H, McKendry R J, Mierins E, Liver J A. Low-dose methotrexate compared with azathioprine in the treatment of rheumatoid arthritis. A twenty-four-week controlled clinical trial. Arthritis Rheum 1987; 30: 361-8.
12 Felson D T, Anderson J J, Meenan R F. The comparative efficacy and toxicity of second-line drugs in rheumatoid arthritis. Results of two meta-analyses. Arthritis Rheum 1990; 33: 1449-61.

13 Pincus T. Rheumatoid arthritis: disappointing long-term outcomes despite successful short term clinical trials. f Clin Epidemiol 1988; 41: 1037-41.

14 Kushner I. Does aggressive therapy of rheumatoid arthritis affect outcome? F Rheumatol 1989; 16: 1-4.

15 Hawley D J, Wolfe F. Are the results of controlled clinical trials and observational studies of second line therapy in rheumatoid arthritis valid and generalizable as measures rheumatoid arthritis valid and generalizable as measures of rheumatoid arthritis outcome: an analysis

16 Situnayake R D, Grindulis K A, McConkey B. Long-term treatment of rheumatoid arthritis with sulphasalazine, gold, or penicillamine: a comparison using life-table methods. Ann Rheum Dis 1987; 46: 177-83.

17 Wijnands M J, Van't Hof M A, Van Leeuwen M A, Van Rijswijk M H, Van de Putte L B, Van Riel P L. Longterm second-line treatment: a prospective drug survival study. Br $\mathcal{F}$ Rheumatol 1992; 31: 253-8.

18 Wolfe F, Hawley D, Cathey M A. Termination of slow acting antirheumatic therapy in rheumatoid arthritis: a 14-year prospective evaluation of 1017 consecutive starts. 14-year prospective evaluation of

19 Pincus T, Marcum S B, Callahan L F. Long term drug therapy for rheumatoid arthritis in seven rheumatology private practices: II. second line drugs and prednisone. f Rheumatol 1992; 19: 1885-94.

20 Thompson P W, Kirwan J R, Barnes C G. Practical results of treatment with disease-modifying antirheumatoid drugs. Br $\mathcal{H}$ Rheumatol 1985; 24: 167-75.

21 Husain $Z$, Runge $L$ A. Treatment complications of rheumatoid arthritis with gold, hydroxychloroquine, D-penicillamine, and levamisole. I Rheumatol 1980; 7: 825-30.

22 Sambrook P N, Browne C D, Champion G D, Day R O, Valance J B, Warwick N. Terminations of treatment with gold sodium thiomalate in rheumatoid arthritis. with gold sodium thiomala

23 Grindulus K A, McConkey B. Outcome of attempts to treat rheumatoid arthritis with gold, penicillamine, sulphasalazine, or dapsone. Ann Rheum Dis 1984; 43: 398-401.

24 Harth M, Davis P, Thompson J M, Menard H, Beaudet F. Comparison between sodium aurothiomalate and auranofin in rheumatoid arthritis: results of a two-year open randomized study. Scand f Rheumatol 1987; 16: 177-84.

25 Amold M H, O'Callaghan J, McCredie M, Beller E M, Kelley D E, Brooks P M. Comparative controlled trials of low-dose weekly methotrexate versus azathioprine in of low-dose weekly methotrexate versus azathioprine in Rheumatol 1990; 29: 120-5.

26 Wooley P H, Griffin J, Panayi G S, Batchelor J R, Welsh $K \mathrm{I}$, Gibson T J. HLA-DR antigens and toxic reaction to sodium aurothiomalate and D-penicillamine in patients with rheumatoid arthritis. $N$ Engl $₹$ Med 1980; 303: $300-2$.

27 Sanchez B, Moreno I, Magarino R, et al. HLA-DRw10 confers the highest susceptibility to rheumatoid arthritis in Spanish population. Tissue Antigens 1990; 36: 174-6.

28 Yelamos J, García-Lozano J R, Moreno I, et al. Association of HLA-DR4-Dw5(DRB1*0405) and DR10 with rheumatoid arthritis in a Spanish population. Arthritis Rheum 1993; 36: 811-4.

29 Seidl L G, Thornton G F, Smith J W, Cluff L E. Studies on the epidemiology of adverse drug reactions. III. Bull fohns Hopkins Hosp 1966; 119: 299-315.

30 Fries J F, Williams C A, Ramey D, Bloch D A. The relative toxicity of disease modifying anti-rheumatic drugs. Arthritis Rheum 1993; 36: 297-306.

31 Sing G, Fries J F, Williams C A, Zatarain E, Spitz P, Bloch D A. Toxicity profiles of disease modifying antirheumatic drugs in RA. $\mathcal{F}$ Rheumatol 1991; 18: 188-98.

32 Kremer J M, Lee J K. A long-term prospective study of the use of methotrexate in rheumatoid arthritis: update after a mean of fifty-three months. Arthritis Rheum 1988; 31: 577-84.

33 Alarcon G S, Tracy I C, Blackburn W D Jr. Methotrexate in rheumatoid arthritis: toxic effects as the major limiting long-term treatment. Arthritis Rheum 1989; 32: 671-6.

34 Sany J, Anaya J M, Lussiez V, Couret $M$, Combe B, Daures J-P. Treatment of rheumatoid arthritis with methotrexate: A prospective open longterm study of 191 cases. F Rheumatol 1991; 18: 1323-7.

35 Weinblatt M E, Kaplan H, Germain B F, et al. Methotrexate in rheumatoid arthritis: a five-year prospective multicenter study. Arthritis Rheum 1994; 37: 1492-8. 